\title{
The Research on the System of Teaching Website Of the “Operating System" Course
}

\author{
Xinxiao Qiao \\ School of information, QiLu University of Technology \\ Jinan, China \\ hopepeace@163.com
}

\begin{abstract}
The paper takes Operator System Course Website for an example to discuss the important contents and problems in particular during the development of excellent course website. Also, some methods and advice are offered for website construction in four aspects, such as the preparation, web site system design, technology and website update and maintenance. Based on B/S structure this paper have designed and developed a Course Website by using the technology of the Java, Jsp and Sql server2008 database. (Abstract)
\end{abstract} System

Keywords- B/S structuret; Courses Web Site; Operator

\section{INTRODUCTION}

In a highly developed information network era, the course website construction plays an important role in University Teaching. It enhances the interaction between students and schools, and strengthen the communication between students and teachers and students to exchange and discussion, and provides a platform for the exchange of teaching and learning and for shared resource.

For the website building course, foreign universities and domestic different, they have a more comprehensive and stable technical team to provide service and technical support. However, the domestic university informatization construction started relatively late. In the process of gradual application of Digital campus theory, On the one hand, the major colleges and universities continue to invest the construction of hardware, software and network system, on the other hand they also develop the implementation of teaching, research, and office management system etc. Finally, a certain scale of informatization construction system has been formed. Compared with foreign countries, the information management system of domestic colleges and universities have a certain gap, on the "institutional settings" and "planning system".

In recent years, with the rapid development of multimedia technology and network technology, the network curriculum unusually fiery. From a large number of domestic literature we can see that The domestic network course although the quantity rapid growth, quality has greatly improved, but still exist many problems in the design. Especially the network curriculum design is a mere formality, some course content is relatively empty, and they are not on the whole course of unified planning according to the teaching goal, so it is impossible to discussion and problem solving learning for learners. Therefore, it is necessary to make research on the design of network course, and establish a set of network curriculum model including the design idea and development process. To develop a website system plays an important role in improving teaching quality and teaching capacity.

\section{THE OVERALL DESIGN OF THE SOFTWARE}

At present, the object of the operating system course website is the teachers and students. Adopting Jsp platform technology based on eclipse and Sql Sever2007 database, three - tiered architecture for witeside system is developed. Teaching website of the operating system includes five modules, namely the login module, module teaching resources, curriculum operation module, communication module, browsing module. This system has set up four permissions, and they are administrators, teachers, students and tourists. This system contact surface is simple direct viewing, simplify operation and use, and interactive is strong.

\section{A. Integrated management system structure}

According to the website of the demand analysis to illustrate, the research group used the "modular design method" in developing the website of the operating system, including some static page. Static page is achieved through hyperlinks, including: introduction of college, teaching resources, curriculum schedule, and other courses. Through these links, students can understand the school situation, and understand the teaching resources of the website.

Based on B/S structure of the operating system teaching website in My Eclipse development environment, based on the J2EE platform, using JSP web programming languages and Struts framework and MySQL database to complete the $\mathrm{B} / \mathrm{S}$ model of library management system. The software adopts JSP to develop friendly and beautiful interface, easy for users to understand, operation. Using MySQL database management system, it can handle large amounts of data, maintain data integrity, security, at the same time.

The design of classroom teaching module. The module can make the students like in the classroom, browse the slides, accept the learning guidance, courses, and can be carried out in class exercises, self-testing learning effect, leak turnover.

Download courseware is a very useful modules, conditional students can download on the computer, for their 
study at ordinary times. An effective complement of the teacher in class teaching.

Problem of communication is to understand the student's opinion and the suggestion of a very effective way. Is also a platform for the communication of teacher and student, the student can put forward to the teacher about learning problems, the teacher can also answer to these questions. Make teachers and students have more communication opportunities and space.

Performance management is a very complicated module, divided into multi-stage administrators and users. Have login detection, retrieve password, cancellation of account. For different permissions users into a different interface, performance management.

Other module is the most common site features, such as: blogroll, campus landscape, etc.

\section{B. Background management system structure}

In view of the web site of a variety of resources, needs to be updated in a timely manner, can maintain the usefulness of website. So I need updating resources administrators. As a result of the news center news approach is to link, so just update links. Updating background information to other modules. And online FAQ module, the spare time is too long of question and answer, to delete. Overall function module chart is shown in figure1.

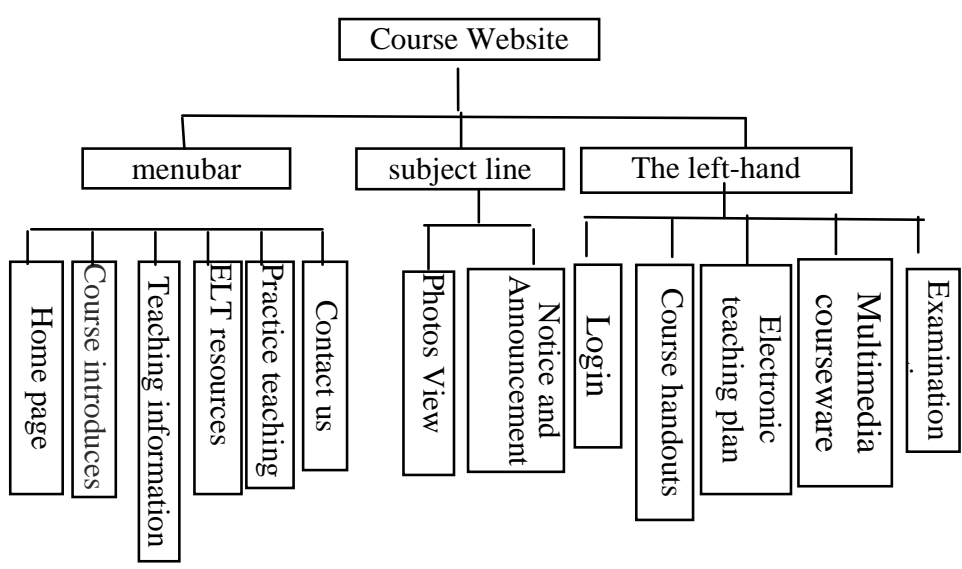

FIGURE I. The overall function structure chart

\section{THE SOFTWARE MAIN FUNCTION MODULE}

This operating system teaching website mainly includes five modules, namely login module, the module of teaching resources, course assignments module, communication module, browse module problem. The following will display the system's main function modules.

\section{A. The login module}

The site four kind of permissions, administrators, teachers, students and tourists, in addition to tourists three other users need to $\log$ in. The teacher who has already logged in can modify personal information, upload data, add the course work etc.

\section{B. Module teaching resources}

The module is mainly teachers as data upload and delete, change, data including announcements, courseware, test paper, the course notes, electronic lesson plans, etc. In the design of data upload here, according to the need to design different types of uploading data, including images, video, audio, documents, etc.

The teacher or administrator can publish teaching resources. The forms and contents of resources can be designed according to section structure form of the course. Administrators and teachers will be able to add the title of the courseware in the background, content, such as word and chart form of document. Resources in the index, the query will be effected according to the title, click on the corresponding title to link to the specific content of under this title. Students can read online resources, but also can be downloaded to the local computer and then to learn, etc.

\section{Coursework module}

Coursework module mainly is the teacher through login to add assignments, set and passing time, corrects students' papers, work, etc. Students can view the homework after the login details, submit assignments, modify the assignments, etc. Teacher is modified, students can see their homework.

Homework release system and resource release system on the data structure is similar, but front desk performance in the form of different, so you can put the two system unified design, teachers can be released to upload your homework, students can download is ready and you can submit your homework assignments, administrators and teachers have management job and delete previously published job right.

\section{Problem of communication module}

This website system problem of communication is similar to a simple BBS, BBS functions, general websites have only through message staff can know they do good or bad, to do their work well through the log in first message of the page. The user shall be carried out in accordance with the interface message and submit.

This page by sevser2008 SQL database with JDBC connection, the message of the each content added to the message in the table in the database, let the webmaster to look at it. This page below to connect to the database using the method is to use the use bean call JavaBean. The administrator can manage to leave a message.

After clicking links jump into action, and call the inside of the list () method, and then return the result set, according to the JSP page. Every page according to post a list of the five elements, and can be paged, click on the name to view a detailed list of posts. Click to view the post a list of names, can appear to view the posts of detailed information, including each of the posts and recovery time. The login user can to delete the posts by their reply. 
According to the above post specific information, click on the right of reply, there will be a return card page, users will be able to reply to the current post, after the success of the reply will show this list in detail, and carried out in accordance with the recovery time has been arranged, which just finished hair will be displayed on the top.

\section{E. Visitors to browse module}

Visitors to browse the main page is all to see the course website all the information, but can't download and upload, etc. Can only view cannot be modified. Which is to check the announcements, anyone can browse, and can be carried out in accordance with the title of fuzzy query, etc. Click on the course information will be shown first teachers, click on the left side of the teachers style also can appear the list, click on the teachers name in displays detailed information.

\section{CONCLUSION}

Through three semester application and popularization of the site, optimize the teaching process, improve the students' innovation ability, improve the teachers' ability. By constructing the operating system teaching platform, to promote students' autonomous learning, cooperative learning, inquiry-based learning has a long-term significance, to the cultivation of innovative talents has played a very important positive role.

\section{ACKNOWLEDGMENT}

This research was financially supported by the teaching research project of QiLu University of Technology (Project No. 2013024) and the project of the education of Shandong province "Twelfth Five Year Plan" key project planning (Project No. 2011GZ078).

\section{REFERENCES}

[1] Jiang Zhihong. "The operation system application based" Curriculum Research Teaching (J). Computer education, 2011 (12): 48 - 51.

[2] Foreman, Joel. Next Generation Educational Technology versus the Lecture. Educause, July/Aug., 2013.

[3] Huber, M.T. Situating the Scholarship of Teaching and Learning: A Cross-Disciplinary Conversation [EB/OL].

[4] http://www.jakesonline.org/ibr.htm, 2012-1 -30.

[5] Jonassen, D. H., Computers as Mind Tools for Schools. Saddle River NJ: Prentice, Hall, 2010.

[6] De Jesus, H., Almeida, P. Questioning styles and students' learning: Four case studies. Educational Psychology, 2010, 24(4).

[7] Li Zhao. Analysis of the value orientation of University Research Learning] . China University Teaching, 2007 (9) : 16.

[8] Yabing Xu, Research and practice of project driven teaching model Journal of Liaoning University of Technology, 13th volume 3rd issue, Vol.13, No.3, 2011 June .

[9] Yabing $\mathrm{Xu}$, Wei Zhou, Research and practice of project driven teaching model, Journal of Liaoning University of Technology (SOCIAL SCIENCE EDITION), 13th volume third issue,Vol.13, No.3, 2011 June
[10] Shi Guangshun, Han Weihuan, Yuan Xiaojie. Nankai University "operating system" course about the construction of [J]. computer education, 2012 (7): 21-24.

[11] Zhang Shuliang, Li Chao,.. NET 2.0+SQL Server network application systems development and intensive case $[\mathrm{M}]$. Tsinghua University 2012

[12] Bret Hartman, Donald J. Flinn. a comprehensive grasp of Web services security [M]. Tsinghua University press, 2014

[13] Li Junli, Bu Xiaoyan. The course website and top quality courses construction [J]. education and occupation, 2003, (14): 137- 139

[14] [Zhang Shengwei 2]. Curriculum website construction in Institutions of higher learning and maintenance [J], education modernization, 2006, (9): 69

[15] Xu Hongxiang, Zheng Guichang, Hao Yue Fei. Construction of excellent courses websites I see [J]. China education information, 2007, (1): 73- 74 